Acta Crystallographica Section E

Structure Reports

Online

ISSN 1600-5368

\section{Mustafa Odabașoğlu, ${ }^{\mathrm{a} *}$ Orhan} Büyükgüngör, ${ }^{b}$ B. Narayana, ${ }^{c}$ A. M. Vijesh ${ }^{\text {c }}$ and H. S. Yathirajan $^{\mathrm{d}}$

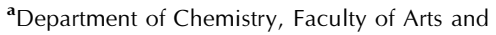
Sciences, Ondokuz Mayıs University, TR-55139 Kurupelit Samsun, Turkey, ${ }^{\mathbf{b}}$ Department of Physics, Faculty of Arts and Sciences, Ondokuz Mayıs University, TR-55139 Kurupelit Samsun, Turkey, 'Department of Studies in Chemistry, Mangalore University, Mangalagangotri 574 199, India, and ${ }^{\mathbf{d}}$ Department of Studies in Chemistry, University of Mysore,

Manasagangotri, Mysore 570 006, India

Correspondence e-mail: muodabas@omu.edu.tr

\section{Key indicators}

Single-crystal X-ray study

$T=296 \mathrm{~K}$

Mean $\sigma(\mathrm{C}-\mathrm{C})=0.005 \AA$

$R$ factor $=0.043$

$w R$ factor $=0.114$

Data-to-parameter ratio $=7.2$

For details of how these key indicators were automatically derived from the article, see http://journals.iucr.org/e.

\title{
(E)-2-Hydroxy-5-methyl-3-[(2-pyridylimino)- methyl]benzaldehyde
}

The title compound, $\mathrm{C}_{14} \mathrm{H}_{12} \mathrm{~N}_{2} \mathrm{O}_{2}$, is stabilized in the solid state as an enol-imine tautomer, with a strong intramolecular $\mathrm{O}-$ $\mathrm{H} \cdots \mathrm{N}$ hydrogen bond, one $\mathrm{C}-\mathrm{H} \cdots \mathrm{N}$ and three $\mathrm{C}-\mathrm{H} \cdots \mathrm{O}$ intermolecular hydrogen bonds, generating edge-fused $\left[S(6) R_{2}^{2}(8) R_{2}^{2}(8) R_{2}^{1}(6)\right]$ motifs. The molecule is approximately planar, with a dihedral angle of $4.40(10)^{\circ}$ between the two aromatic rings.

\section{Comment}

Schiff bases are used as substrates in the preparation of a number of industrial and biologically active compounds via ring closure, cycloaddition and replacement reactions. Moreover, Schiff bases are also known to have biological activities, such as antimicrobial (El-Masry et al., 2000; Pandey et al., 1999), antifungal (Singh \& Dash, 1988), antitumour (Hodnett \& Dunn, 1970; Desai et al., 2001) and herbicidal properties (Holla et al., 2000). Schiff bases have also been employed as ligands for the complexation of metal ions (Odabaşoğlu et al., 2007; Aydoğan et al., 2001). On the industrial scale, they have a wide range of applications, such as dyes and pigments (Taggi et al., 2002). In continuation of our work on Schiff bases (Yathirajan et al., 2007; Odabaşoğlu et al., 1999, 2003, 2004, 2005a,b, 2006, 2007; Ersanlı et al., 2003), the title new Schiff base, (I), was synthesized and its crystal structure is reported (Fig. 1, Table 1).

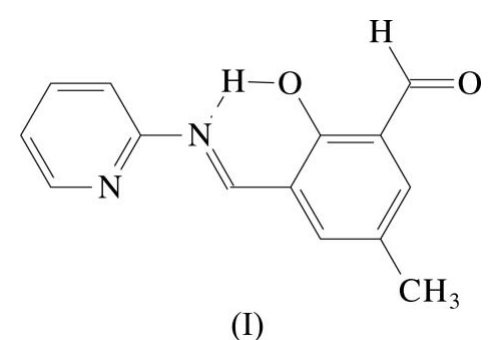

There are two possible types of intramolecular hydrogen bonds in salicylaldehyde Schiff bases, as exhibited by the ketoamine $(\mathrm{N} \cdots \mathrm{H}-\mathrm{O})$ and enol-imine $(\mathrm{N}-\mathrm{H} \cdots \mathrm{O})$ tautomeric forms. Salicylaldehyde Schiff bases have been found in the keto form (Odabaşoğlu et al., 2003), in the enol form (Leardini et al., 1998; Odabaşoğlu et al., 2005b) and as enol/keto mixtures (Nazır et al., 2000). The present X-ray crystallographic investigation shows that compound (I) prefers the enol-imine tautomeric form.

Compound (I) displays a strong intramolecular hydrogen bond (Table 2) involving atoms N1 and O1, a common feature of salicylidene systems. In (I), molecules are linked through an $\mathrm{O}-\mathrm{H} \cdots \mathrm{N}$ intramolecular hydrogen bond, and molecules are
Received 16 March 2007 Accepted 19 March 2007 
linked through three $\mathrm{C}-\mathrm{H} \cdots \mathrm{O}$ and one $\mathrm{C}-\mathrm{H} \cdots \mathrm{N}$ intermolecular hydrogen bonds. These hydrogen bonds generate edge-fused $\left[S(6) R_{2}^{2}(8) R_{2}^{2}(8) R_{2}^{1}(6)\right]$ motifs (Etter, 1990) (Fig. 2 and Table 2). The molecule is almost planar, with dihedral angles of $0.47(8)^{\circ}$ between the $\mathrm{C} 1-\mathrm{C} 6$ ring and the intramolecularly hydrogen-bonded ring, and $4.40(10)^{\circ}$ between the hydrogen-bonded ring and the pyridyl ring.

\section{Experimental}

A mixture of 5-hydroxy-2-methylisophthalaldehyde (2.58 g, $0.01 \mathrm{~mol})$ and pyridin-2-amine $(0.94 \mathrm{~g}, 0.01 \mathrm{~mol})$ in absolute ethanol $(20 \mathrm{ml})$ containing two drops of 4 Msulfuric acid was refluxed for about $4 \mathrm{~h}$. On cooling, the solid which separated was filtered off and recrystallized from ethanol (m.p. 393-395 K). Analysis for $\mathrm{C}_{14} \mathrm{H}_{12} \mathrm{~N}_{2} \mathrm{O}_{2}$ : found (calculated): C 69.83 (69.99), H 4.96 (5.03), N $11.52 \%$ $(11.66 \%)$.

\section{Crystal data}

$\mathrm{C}_{14} \mathrm{H}_{12} \mathrm{~N}_{2} \mathrm{O}_{2}$

$M_{r}=240.26$

Monoclinic, $P c$

$a=7.4049$ (8) ^

$b=4.2957(3) \AA$

$c=20.154(2) \AA$

$\beta=108.847(8)^{\circ}$

\section{Data collection}

Stoe IPDSII diffractometer Absorption correction: integration ( $X$-RED32; Stoe \& Cie, 2002)

$T_{\min }=0.954, T_{\max }=0.989$

\section{Refinement}

$R\left[F^{2}>2 \sigma\left(F^{2}\right)\right]=0.043$

$w R\left(F^{2}\right)=0.114$

$S=0.99$

1184 reflections

164 parameters

Table 1

Selected geometric parameters $\left(\AA,^{\circ}\right)$.

\begin{tabular}{lrlr}
\hline $\mathrm{C} 1-\mathrm{C} 9$ & $1.432(5)$ & $\mathrm{C} 9-\mathrm{N} 1$ & $1.282(4)$ \\
$\mathrm{C} 2-\mathrm{O} 1$ & $1.349(4)$ & $\mathrm{C} 10-\mathrm{N} 1$ & $1.422(4)$ \\
$\mathrm{N} 1-\mathrm{C} 9-\mathrm{C} 1$ & $121.9(3)$ & $\mathrm{C} 9-\mathrm{N} 1-\mathrm{C} 10$ & $120.5(3)$ \\
$\mathrm{C} 1-\mathrm{C} 9-\mathrm{N} 1-\mathrm{C} 10$ & $-177.8(3)$ & & \\
\hline
\end{tabular}

Table 2

Hydrogen-bond geometry $\left(\AA,^{\circ}\right)$.

\begin{tabular}{lllll}
\hline$D-\mathrm{H} \cdots A$ & $D-\mathrm{H}$ & $\mathrm{H} \cdots A$ & $D \cdots A$ & $D-\mathrm{H} \cdots A$ \\
\hline $\mathrm{O} 1-\mathrm{H} 1 \cdots \mathrm{N} 1$ & 0.82 & 1.85 & $2.585(3)$ & 148 \\
$\mathrm{C} 9-\mathrm{H} 9 \cdots 2^{\mathrm{i}}$ & 0.93 & 2.79 & $3.620(4)$ & 150 \\
$\mathrm{C} 14-\mathrm{H} 14 \cdots \mathrm{O} 1^{\mathrm{i}}$ & 0.93 & 2.71 & $3.546(5)$ & 151 \\
$\mathrm{C} 6-\mathrm{H} 6 \cdots \mathrm{O} 2^{\mathrm{i}}$ & 0.93 & 2.77 & $3.612(4)$ & 152 \\
$\mathrm{C} 7-\mathrm{H} 7 \cdots \mathrm{N} 2^{\mathrm{ii}}$ & 0.93 & 2.73 & $3.606(5)$ & 158
\end{tabular}

Symmetry codes: (i) $x-1, y-1, z$; (ii) $x+1, y+1, z$.

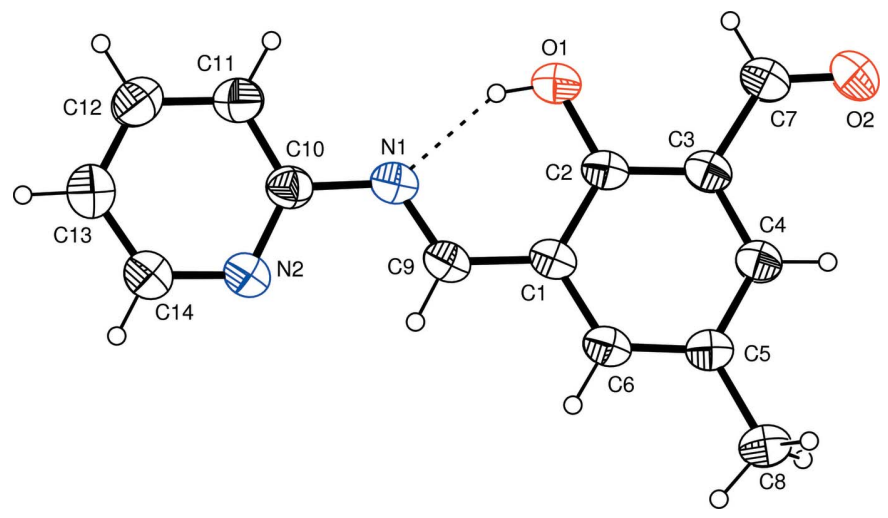

Figure 1

The molecular structure of (I), showing the atomic numbering scheme, with displacement ellipsoids drawn at the $30 \%$ probability level. The intramolecular hydrogen bond is shown as a dashed line.

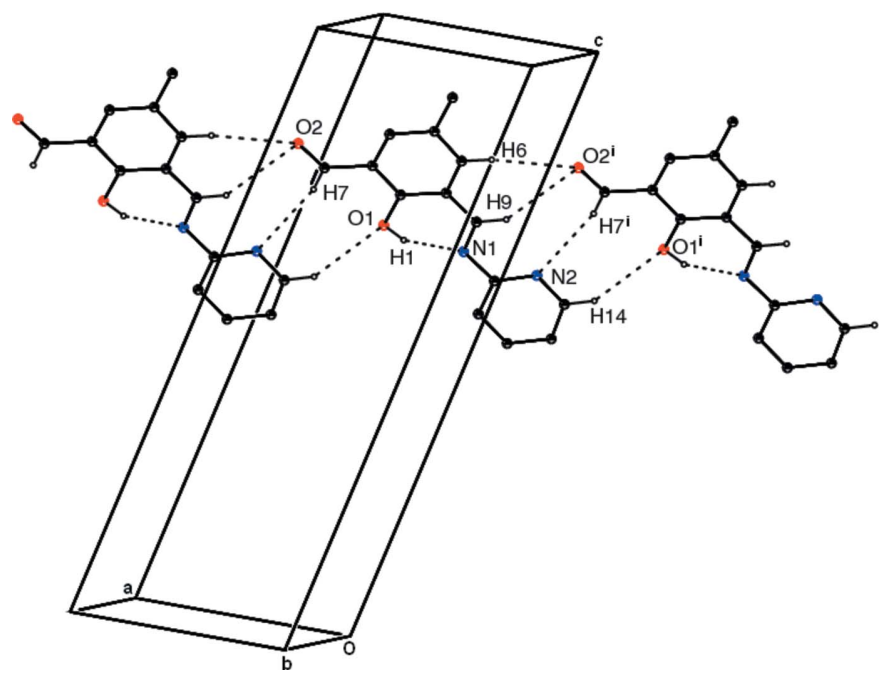

Figure 2

Part of the crystal structure of (I). For the sake of clarity, $\mathrm{H}$ atoms not involved in the hydrogen-bonding motifs have been omitted. Hydrogen bonds are shown as dashed lines. [Symmetry code: (i) $1-x, 1-y, z$.]

In the absence of significant anomalous scattering effects, 160 Friedel pairs were merged. All $\mathrm{H}$ atoms were treated as riding on their parent atoms, with $\mathrm{C}-\mathrm{H}=0.93 \AA$ and $U_{\text {iso }}(\mathrm{H})=1.2 U_{\text {eq }}(\mathrm{C}, \mathrm{N})$ for aromatic, aldehydic and imino $\mathrm{H}$, with $\mathrm{C}-\mathrm{H}=0.96 \AA$ and $U_{\text {iso }}(\mathrm{H})$ $=1.5 U_{\text {eq }}(\mathrm{C})$ for methyl $\mathrm{H}$, and with $\mathrm{O}-\mathrm{H}=0.82 \AA$ and $U_{\text {iso }}(\mathrm{H})=$ $1.5 U_{\text {eq }}(\mathrm{O})$ for the $\mathrm{H}$ atom of the hydroxyl group.

Data collection: $X$-AREA (Stoe \& Cie, 2002); cell refinement: $X$-AREA; data reduction: $X$-RED32 (Stoe \& Cie, 2002); program(s) used to solve structure: SHELXS97 (Sheldrick, 1990); program(s) used to refine structure: SHELXL97 (Sheldrick, 1997); molecular graphics: ORTEP-3 for Windows (Farrugia, 1997); software used to prepare material for publication: WinGX (Farrugia, 1999).

The authors acknowledge the Faculty of Arts and Sciences, Ondokuz Mayis University, Turkey, for the use of the Stoe IPDSII diffractometer (purchased under grant F.279 of the University Research Fund). 


\section{organic papers}

\section{References}

Aydoğan, F., Öcal, N., Turgut, Z. \& Yolaçan, C. (2001). Bull. Korean Chem. Soc. 22, $476-480$

Desai, S. B., Desai, P. B. \& Desai, K. R. (2001). Heterocycl. Commun. 7, 8390.

El-Masry, A. H., Fahmy, H. H. \& Abdelwahed, S. H. A. (2000). Molecules, 5, $1429-1438$

Ersanlı, C. C., Albayrak, Ç., Odabaşoğlu, M. \& Erdönmez, A. (2003). Acta Cryst. C59, o601-0602.

Etter, M. C. (1990). Acc. Chem. Res. 23, 120-126.

Farrugia, L. J. (1997). J. Appl. Cryst. 30, 565.

Farrugia, L. J. (1999). J. Appl. Cryst. 32, 837-838.

Hodnett, E. M. \& Dunn, W. J. (1970). J. Med. Chem. 13, 768-7.

Holla, B. S., Rao, B. S., Shridhara, K. \& Akberali, P. M. (2000). Il Farmaco, 55, 338-344.

Leardini, R., McDougald, G., McNab, H., Nanni, D. \& Parsons, S. (1998). Acta Cryst. C54, 1360-1362.

Nazır, H., Yıldız, M., Yılmaz, H., Tahir, M. N. \& Ülkü, D. (2000). J. Mol. Struct. 524, 241-250.

Odabaşoğlu, M., Albayrak, Ç. \& Büyükgüngör, O. (2004). Acta Cryst. E60, o142-o144.
Odabaşoğlu, M., Albayrak, C. \& Büyükgüngör, O. (2005a). Acta Cryst. C61, o240-o242.

Odabaşoğlu, M., Albayrak, Ç. \& Büyükgüngör, O. (2005b). Acta Cryst. E61, o425-o426.

Odabaşoğlu, M., Albayrak, C. \& Büyükgüngör, O. (2006). Acta Cryst. E62, o1094-o1096.

Odabaşoğlu, M., Albayrak, Ç., Büyükgüngör, O. \& Lönnecke, P. (2003). Acta Cryst. C59, o616-0619.

Odabaşoğlu, M., Arslan, F., Ölmez, H. \& Büyükgüngör, O. (2007). Dyes Pigments, DYPI-2425. In the press.

Odabaşoğlu, M., Turgut, G. \& Karaer, H. (1999). Phosphorus Sulfur Silicon, 152, 9-25.

Pandey, S. N., Sriram, D., Nath, G. \& De Clercq, E. (1999). Il Farmaco, 54, 624628.

Sheldrick, G. M. (1990). Acta Cryst. A46, 467-473.

Sheldrick, G. M. (1997). SHELXL97. University of Göttingen, Germany.

Singh, W. M. \& Dash, B. C. (1988). Pesticides, 22, 33-37.

Stoe \& Cie (2002). $X$-AREA (Version 1.18) and $X$-RED32 (Version 1.04). Stoe \& Cie, Darmstadt, Germany.

Taggi, A. E., Hafez, A. M., Wack, H., Young, B., Ferraris, D. \& Lectka, T. (2002). J. Am. Chem. Soc. 124, 6626-6635.

Yathirajan, H. S., Sarojini, B. K., Narayana, B., Sunil, K. \& Bolte, M. (2007). Acta Cryst. E63, o1398-o1399. 